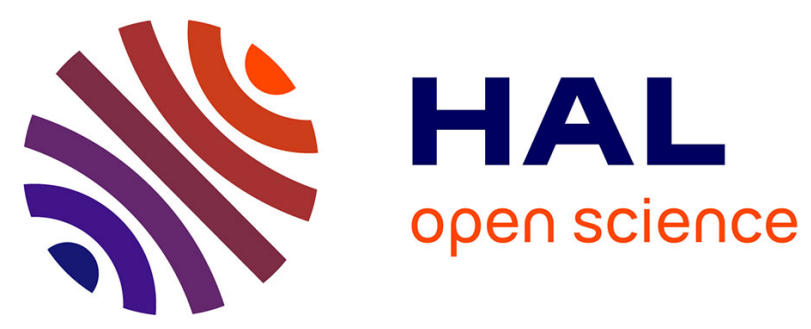

\title{
Strain Rate Dependent Hardening of DP600 Sheet Metal for Large Strains Under In-plane Biaxial Loadings
}

Wei Liu, Dominique Guines, Lionel Leotoing, Eric Ragneau

\section{To cite this version:}

Wei Liu, Dominique Guines, Lionel Leotoing, Eric Ragneau. Strain Rate Dependent Hardening of DP600 Sheet Metal for Large Strains Under In-plane Biaxial Loadings. 19th International ESAFORM Conference on Material Forming (ESAFORM 2016), Apr 2016, Nantes, France. pp.060004, 10.1063/1.4963440 . hal-01394756

\section{HAL Id: hal-01394756 https://hal.science/hal-01394756}

Submitted on 9 Nov 2016

HAL is a multi-disciplinary open access archive for the deposit and dissemination of scientific research documents, whether they are published or not. The documents may come from teaching and research institutions in France or abroad, or from public or private research centers.
L'archive ouverte pluridisciplinaire HAL, est destinée au dépôt et à la diffusion de documents scientifiques de niveau recherche, publiés ou non, émanant des établissements d'enseignement et de recherche français ou étrangers, des laboratoires publics ou privés. 


\title{
Strain Rate Dependent Hardening of DP600 Sheet Metal for Large Strains Under In-plane Biaxial Loadings
}

\author{
Liu W. ${ }^{1, a)}$, Guines D. ${ }^{2, \text { b) }}$, Léotoing L. ${ }^{2, c)}$, Ragneau E. ${ }^{2, \text { d) }}$ \\ ${ }^{1}$ School of Materials Science and Engineering, Wuhan University of Technology, P.R. China \\ ${ }^{2}$ Université Européenne de Bretagne, INSA-LGCGM-EA3913, 20 Av. des Buttes de Coësmes, CS 70839, 35708 \\ Rennes Cédex 7, France \\ a)weiliu@whut.edu.cn \\ b) Corresponding author: dominique.guines@insa-rennes.fr \\ ${ }^{c)}$ lionel.leotoing@insa-rennes.fr \\ d) eric.ragneau@insa-rennes.fr
}

\begin{abstract}
In this work, an in-plane biaxial tensile test of cruciform specimen is performed to identify the visco-plastic hardening behaviour of metallic sheets for both large strains and intermediate strain rates at room temperature. Firstly, an optimal shape of the specimen is suggested. Then, dynamic biaxial tensile tests are carried out for a dual phase DP600 steel sheet. Experimental forces on the two axes of the specimen are measured during the test and strains in the central area of the specimen are post-treated by means of Digital Image Correlation (DIC) technique. Finally, considering a Hill48 anisotropic yield criterion, two strain rate dependent hardening laws are identified thanks to an inverse procedure based on a Finite Element (FE) modelling of the biaxial tensile test and on the experimental data mentioned above. The identified biaxial flow curves are then compared with the ones from a classical uniaxial tensile test.
\end{abstract}

\section{INTRODUCTION}

In sheet metal forming processes, the material is deformed under multi-axial states and is subjected to large strains. Hence, the identification of material constants, corresponding to the different behaviour models (yield criterion, hardening, ...), under biaxial tensile state has become a basic issue for the characterization of phenomenological models.

In the last decades, the in-plane biaxial tensile test has been used to capture anisotropic elastic constants or 2D yield surfaces of metallic sheets by different authors [1, 2]. Recently, based on works of Kuwabara [3], a standardized flat cruciform specimen shape has been proposed (international standard ISO16842 [4]). Biaxial stressstrain curves and initial or subsequent contours of plastic work of sheet metals subject to biaxial tension at arbitrary stress ratios can be determined. Stress and strain fields are assumed to be homogeneous in the specimen central zone. Stresses are evaluated analytically from measured forces by considering an equivalent cross section and strains in the central zone are obtained from gauge sensor.

More recently, the development of optical full-field measurement techniques for analysing heterogeneous strain fields, such as DIC technique, coupled with an inverse strategy of parameter identification, including the FE model of the specimen, have led to new characterization methodologies of material plastic behaviours. Based on this new methodology, several works have been proposed in the last years (Teaca [5], Prates [6], Zhang [7]).

Several attempts of cruciform shape design to reach large strains have also been presented. Green [8] has proposed specimen geometry with a central section thinner than the rest of the specimen and seven parallel slots in each arm. Tasan [9] has demonstrated that a significant thickness reduction in the centre is necessary to reach fracture under a biaxial strain path. Souto et al. [10] have proposed an innovative numerical optimization process for the design of heterogeneous tests. Results show that the best specimen shape is the cruciform shape for promoting a rich mechanical information when biaxial loading path is applied. However, in all works presented above, only 
relatively low values of equivalent plastic strain (close to those obtained in uniaxial tension) are reached before plastic instabilities occur.

For characterizations at large strains, Zidane [11] have proposed a specific cruciform shape to determine the whole forming limit curves (FLC) of metallic sheet. In this specimen, a central thickness reduction is defined by a curved profile to obtain the onset of necking at the central point. Strain path is then completely defined by the displacement ratio imposed on the two axes of the cross specimen. Recently, an optimized cruciform specimen with a flat thickness reduced central section, four slots in each arm and radius fillet between two arms, as shown in Fig. 1, has been proposed from a parametric study by Liu [12]. This shape has been validated by experiments, performed on the same experimental device than the one used by Zidane's, for large strains and static applications for the determination of hardening law parameters up to $30 \%$ of equivalent plastic strain on an AA5086 aluminium alloy.

Concerning material behaviour investigations under biaxial tensile strain path at intermediate strain rates, Grolleau [13] have proposed a dynamic bulge testing device to identify the hardening law of aluminium alloy A1611-T4 sheet at high strain rate up to $500 \mathrm{~s}^{-1}$. A movable bulge cell is designed and installed in a split Hopkinson pressure bar (SHPB) system. Ramezani [14] have also introduced a similar high strain rate bulge test technique on the basis of SHPB system. In order to investigate the material behaviour under dynamic and different biaxial stress state, Shimamoto et al. [15] have developed a servo-hydraulic dynamic biaxial loading device. The in-plane dynamic biaxial test on cruciform specimen is carried out at $2 \mathrm{~m} / \mathrm{s}$ to reveal the crack extension behaviour of aluminium alloy AA7075-T6.

In the present work, the specific biaxial tensile device with four independent servo-hydraulic actuators already used in $[7,11,12]$ to perform in-plane biaxial tensile tests on cruciform specimens at quasi-static strain rate is adopted to performed quasi-static and dynamic biaxial tensile tests on Dual Phase DP600 steel specimens. Strainrate dependent hardening of this material is characterized at room temperature. Moderate strain rates (up to $10 \mathrm{~s}^{-1}$ ) and large strains (up to $40 \%$ of equivalent plastic strain) are tested. The deformation-induced thermal effects are not considered in this study even if this phenomenon can be significant at tested strain rates which are closer to the adiabatic limit. Experiments being performed at room temperature, temperature sensitivity of flow stress can be considered as a secondary material factor. The identified biaxial flow stress curves are then compared with uniaxial ones for the quasi-static and intermediate strain rates to show the benefits of the proposed methodology.

\section{BIAXIAL TENSILE TESTS}

\section{Testing specimen}

Dual Phase DP600 steel provided in sheets of thickness $2 \mathrm{~mm}$ is used in this study. Main dimensions of the specimen shape are given in Fig. 1.
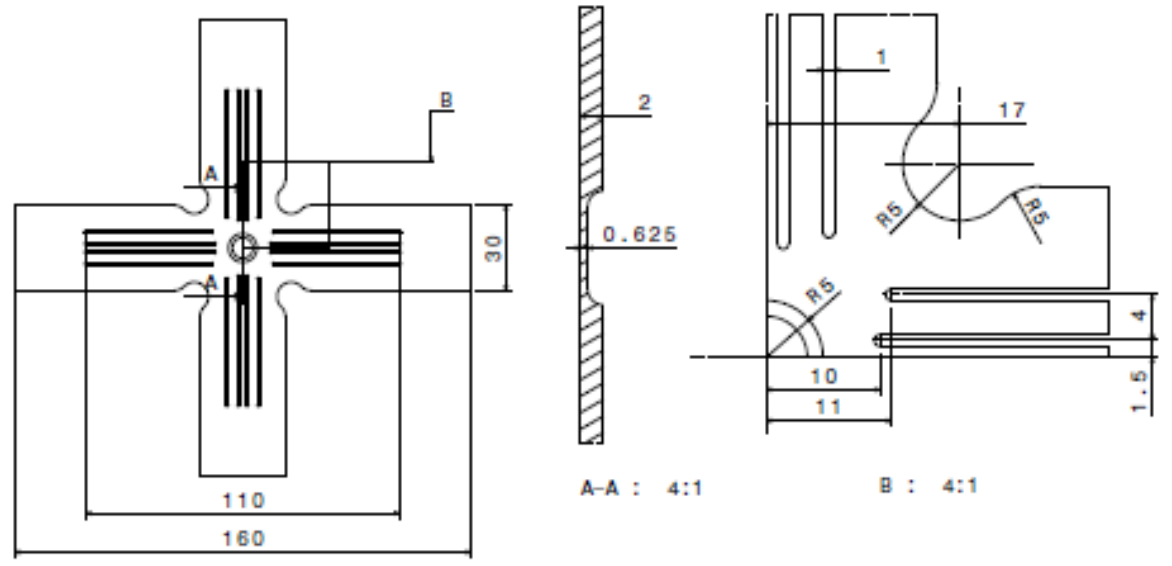

FIGURE 1. Geometry of the cruciform shape

The ends of each arm of the specimen used to connect the specimen to the actuator rod are not presented in this figure but a general view of the whole specimen is shown in Fig. 2. This geometry has been validated in [12] for the 
characterization of the hardening behaviour for large strains (up to 30\%) in quasi-static conditions. The thickness reduction of the central zone is manufactured by milling and slits are obtained by a wire cut electric discharge machine.

\section{Experimental device}

The biaxial machine is equipped of four independent servo-hydraulic actuators. Each end of the cruciform specimen is connected to an actuator rod through a mechanical part assembly as shown in Fig. 2. For dynamic tests, the impactor is accelerated along the sliding bar to obtain the specific velocity before the specimen is loaded. Due to the initial impact, oscillations appear on force signal. To reduce these oscillations a damping layer of elastomer is setting up at the interface between the sliding bar and impactor. The thickness of damping layer is $3 \mathrm{~mm}$. After the impact, the displacement of the sliding bar is transmitted to each specimen end through the load sensor and the biarticulated link. During the test, the velocity is maintained almost constant due to the inertia effect of impactor.

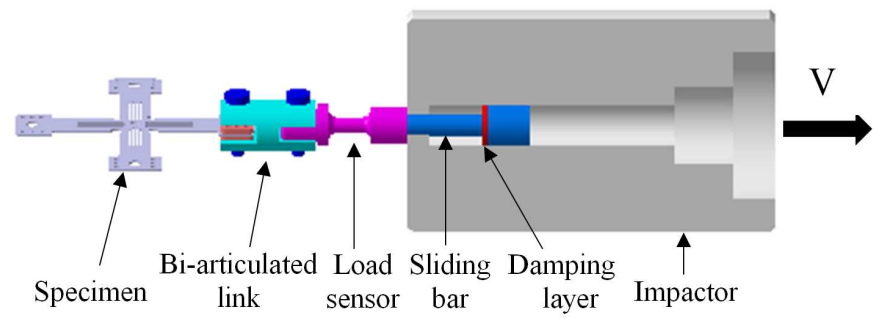

FIGURE 2. Dynamic biaxial device with damping layer

Tensile tests on cruciform specimens are carried out at three loading velocities: $0.02 \mathrm{~mm} / \mathrm{s}, 1 \mathrm{~mm} / \mathrm{s}$ and $250 \mathrm{~mm} / \mathrm{s}$. The experimental forces along the two perpendicular directions are measured by deformation gauge load sensors. A high speed camera is adopted to record the surface deformation of the central zone of specimen. Digital image correlation (DIC) technique is used to determine the true strain field on the specimen surface. Details about posttreatment by DIC technique can be found in [12]. The evolutions of the major and minor principal strains at the central point of the specimen are shown in Figs. 3a, 3c, 3e for respectively the three velocities $0.02 \mathrm{~mm} / \mathrm{s}, 1 \mathrm{~mm} / \mathrm{s} \mathrm{and}$ $250 \mathrm{~mm} / \mathrm{s}$ corresponding to an approximate strain rate of $0.005 \mathrm{~s}^{-1}, 0.2 \mathrm{~s}^{-1}$ and $20 \mathrm{~s}^{-1}$. An equivalent plastic strain of more than $30 \%$ is observed whatever the tested velocity. Due to little asynchronization between the two tensile directions at the beginning of tests, major principal strain curves does not exactly coincide with the minor principal strain.

\section{PARAMETER IDENTIFICATION OF HARDENING BEHAVIOR}

\section{Procedure of identification}

The calibration of material constants of DP600 strain rate dependent hardening behavior is obtained by an inverse procedure based on a finite element (FE) modelling of the biaxial test coupling with an optimization platform. The global experimental forces along the two arms are applied to the FE model. The experimental database is made up of the time evolutions of the major and minor strains for the three tested velocities. The experimental and simulated principal strains at the central point of specimen are compared to identify the parameters of strain rate dependent hardening laws. The cost function to be minimized is defined as follows:

$$
Q=\frac{1}{2 n} \sqrt{\sum_{i=1}^{2}\left(\sum_{j=1}^{n}\left(\varepsilon_{i}^{s i m}\left(t_{j}\right)-\varepsilon_{i}^{\exp }\left(t_{j}\right)\right)^{2} / \sum_{j}^{n}\left(\varepsilon_{i}^{\exp }\left(t_{j}\right)\right)^{2}\right)}
$$

Where $n$ is the total number of time points, $\varepsilon_{1}^{\text {sim }}$ and $\varepsilon_{2}^{s i m}$ are the simulated major and minor principal strains at the central element of the FE model and $\varepsilon_{1}^{\exp }$ and $\varepsilon_{2}^{\exp }$ are the experimental principal strains at the central point of specimen. The optimization algorithm of Simplex has been chosen to optimize the material parameters. In order 
to make sure that the global minimum is found, different initial values are compared and more feasible initial sets are chosen for inverse analysis.

\section{Material models}

Considering isotropic elasticity for the DP600 steel, elastic constants are defined by the Young's modulus, $E=200 G P a$, and the Poisson's ratio, $v=0.3$. The associated normal flow rule and an isotropic hardening model are assumed. Two different formulations of the general strain rate dependent hardening behaviour, given in equations 1) and 2), are considered. The first one, the Ludwick's law, presents a stiffening behaviour whereas the second one, the Voce's law, shows a saturating behaviour. From experimental observations, strain rate dependence is associated to the initial yield stress $\sigma_{0}$ for the two hardening laws.

$$
\begin{gathered}
\bar{\sigma}=\sigma_{0} \dot{\bar{\varepsilon}}^{m_{1}}+K \bar{\varepsilon}_{p}{ }^{n} \dot{\bar{\varepsilon}}^{m_{2}} \\
\bar{\sigma}=\sigma_{0} \dot{\bar{\varepsilon}}^{m_{1}}+K\left(1-\exp \left(-n \bar{\varepsilon}_{p}^{n}\right)\right) \dot{\bar{\varepsilon}}^{m_{2}}
\end{gathered}
$$

Based on previous works [12], a Hill48 yield criterion is chosen to describe the DP600 plastic anisotropy. Hill's parameters are calculated by the three anisotropic coefficients defined for the three orientations $\left(0^{\circ}, 45^{\circ}\right.$ and $\left.90^{\circ}\right)$ from the rolling direction: $\mathrm{r}_{0}=0.89 ; \mathrm{r}_{45}=0.85 ; \mathrm{r}_{90}=1.12$.

\section{RESULTS}

The material constants identified for the two hardening laws are presented in Table 1. As it can be seen, relatively close cost functions are found, about $9 \%$ whatever the law. For the two hardening laws, a small strain rate dependency of the initial yield function is observed (low values of $m_{1}$ ) while a more important one is observed on the hardening behaviour.

TABLE 1. Identified hardening parameters

\begin{tabular}{lcccccc}
\hline Hardening Law & $\boldsymbol{\sigma}_{\mathbf{0}}(\mathbf{M P a})$ & $\mathbf{K}(\mathbf{M P a})$ & $\mathbf{n}$ & $\mathbf{m}_{\mathbf{1}}$ & $\mathbf{m}_{\mathbf{2}}$ & $\begin{array}{c}\text { Error } \\
\mathbf{Q}(\boldsymbol{\%})\end{array}$ \\
\hline Ludwick & 339.2 & 839.7 & 0.3864 & 0.0052 & 0.0158 & 8.69 \\
\hline Voce & 437.9 & 446.2 & 8.2412 & 0.0032 & 0.0245 & 9.63 \\
\hline
\end{tabular}

The simulated principal strains have been compared with the experimental ones, as shown in Fig. 3. Although the simulated principal strains are lower than the experimental ones at the beginning of tests, the observed trends of simulated principal strains are in relatively good agreement with the experimental ones for principal strains above $3 \%$ whatever the strain rate considered.

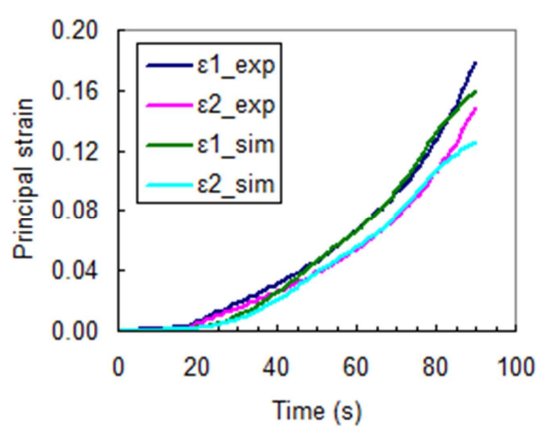

(a) $0.02 \mathrm{~mm} / \mathrm{s}$, Ludwick

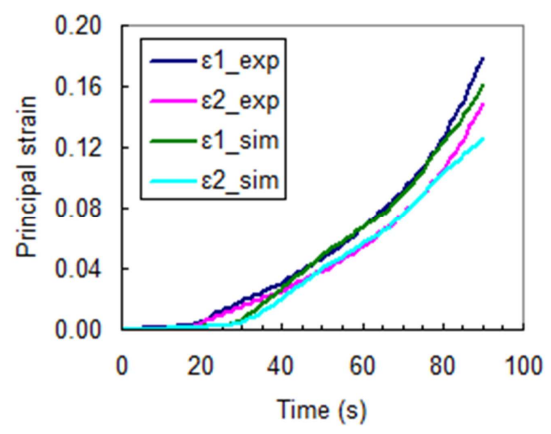

(b) $0.02 \mathrm{~mm} / \mathrm{s}$, Voce 


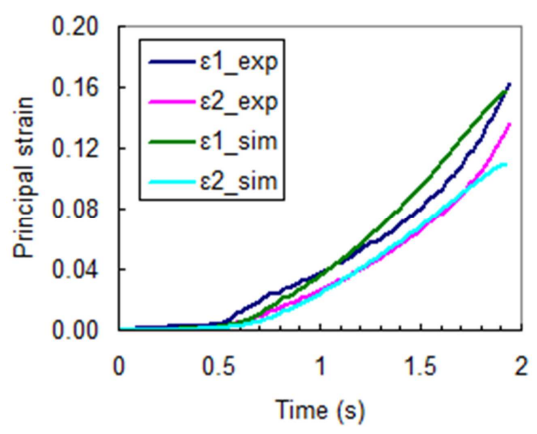

(c) $1 \mathrm{~mm} / \mathrm{s}$, Ludwick

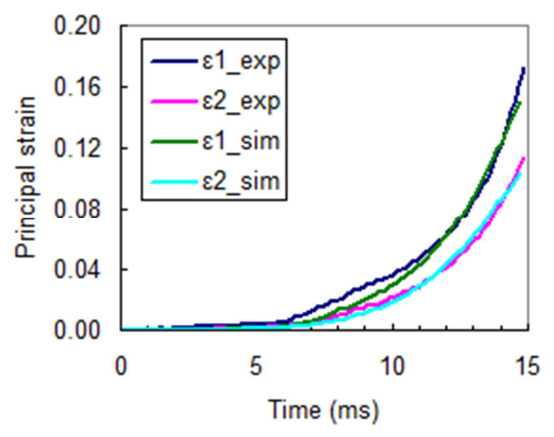

(e) $250 \mathrm{~mm} / \mathrm{s}$, Ludwick

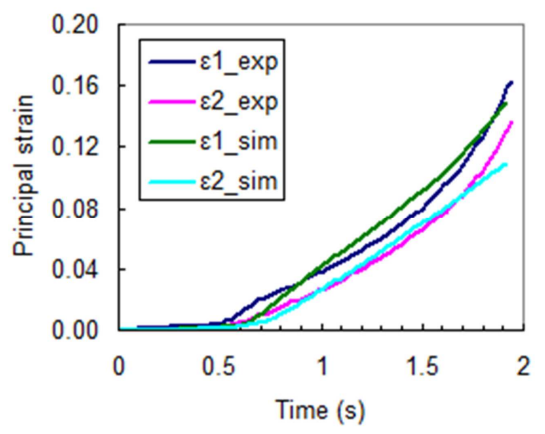

(d) $1 \mathrm{~mm} / \mathrm{s}$, Voce

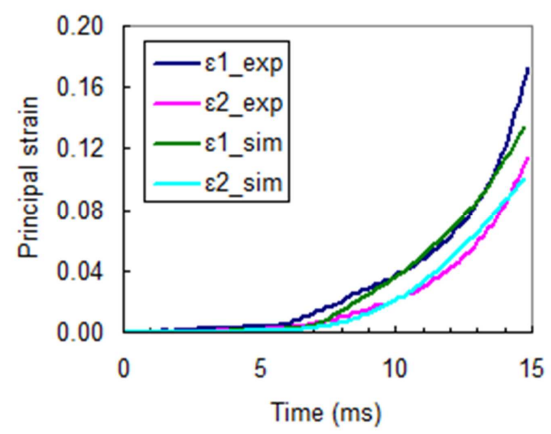

f) $250 \mathrm{~mm} / \mathrm{s}$, Voce

FIGURE 3. Comparison of experimental and simulated strain curves

The biaxial flow stress curves identified on the basis of Ludwick and Voce models are compared in Fig. 4a. It can be observed that the two hardening laws identified for an equivalent plastic range from 0 to $30 \%$ are very close. This result demonstrated that the hardening is well described, whatever the law, until 30\%. The Fig. 4b shows a comparison of Ludwick and Voce hardening laws identified from uniaxial tests, i.e. up to $20 \%$ equivalent plastic strain, on same DP600 steel sheets (not presented in this paper).

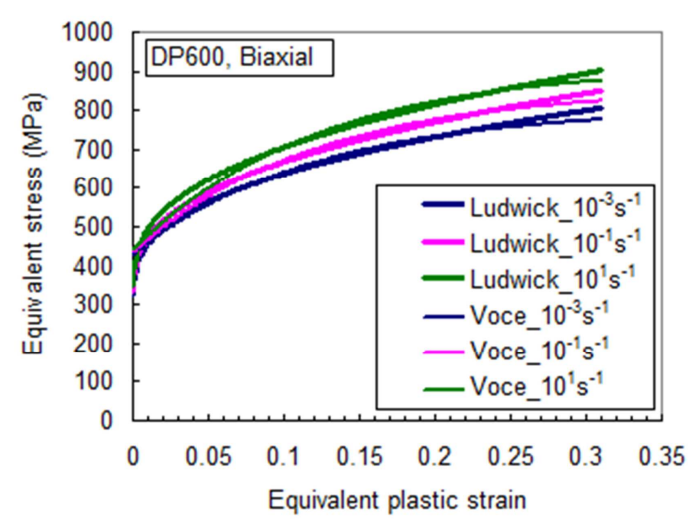

(a). From biaxial tensile tests

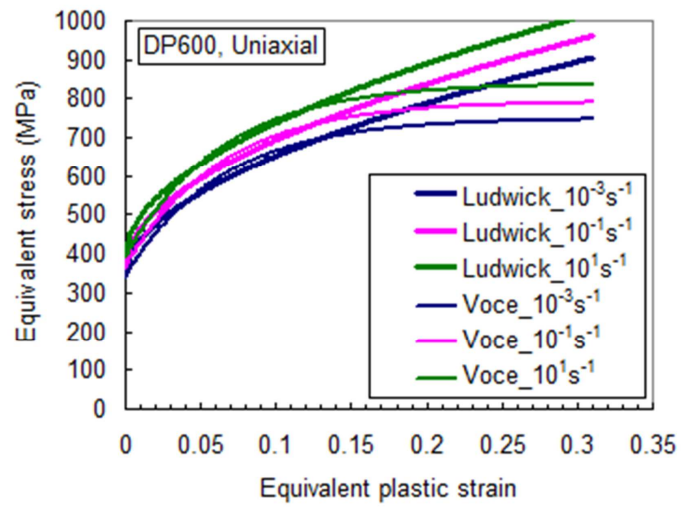

(b). From uniaxial tensile tests

FIGURE 4. Identified Ludwick and Voce strain rate dependent hardening laws 
As it can be seen, compared to Fig. 4a, very different results are observed for large strains both for Voce and Ludwick formulations. Therefore, as already shown, the dynamic biaxial tensile test is validated to identify the hardening behaviour for large strains and also strain rate hardening dependency under biaxial tensile state.

\section{CONCLUSION}

In this work, the potential of the in-plane biaxial tensile test on cross specimen to characterize the strain rate dependent hardening behaviour of metallic sheets under large strains (up to $30 \%$ of the equivalent strain level) has been investigated. Due to the complex specimen shape, exhibiting non-homogeneous strain and stress fields, a numerical FE model of the dynamic biaxial tensile test used in an inverse calibration procedure is needed. Strain rate sensitivity of DP600 metallic sheets in an intermediate strain rate range has been identified considering two different hardening models (Ludwick and Voce) and Hill48 anisotropic plastic criterion.

Like the bulge test, in-plane biaxial tensile test permits the identification of hardening behaviour up to large strains. Nevertheless, contrary to the bulge test, strain path is controlled by actuator displacements in the two main directions of the cross specimen and effects of strain path changes can be investigated without any restriction about the type of non-linear path. This feature provides interesting perspectives for the identification of advanced hardening behaviours like isotropic-kinematical combined models.

\section{REFERENCES}

1. W. Muller, K. Pohlandt, New experiments for determining yield loci of sheet metal, Journal of Materials Processing Technology, 60 (1996) 643-648.

2. M. Merklein, W. Hubnatter, M. Geiger, Characterization of yielding behavior of sheet metal under biaxial stress condition at elevated temperatures, CIRP Annals - Manufacturing Technology 57 (2008) 269-274.

3. T. Kuwabara, S. Ikeda, K. Kuroda, Measurement and analysis of differential work hardening in cold-rolled steel sheet under biaxial tension, Journal of Materials Processing Technology, 80-81 (1998) 517-523.

4. International Standard ISO16842, Metallic materials - Sheet and strip - Biaxial tensile testing method using a cruciform test piece, 2014.

5. M. Teaca, I. Charpentier, M. Martiny, G. Ferron, Identification of sheet metal plastic anisotropy using heterogeneous biaxial tensile tests, International Journal of Mechanical Sciences 52 (2010) 572-580.

6. P. Prates, M. Oliveira, J. Fernandes, A new strategy for the simultaneous identification of constitutive laws parameters of metal sheets using a single test, Computational Materials Science 85 (2014) 102-120.

7. S. Zhang, L. Leotoing, D. Guines, S. Thuillier, Potential of the cross biaxial test for anisotropy characterization based on heterogeneous strain field, Experimental Mechanics, (2015) 55:817-835.

8. D.E. Green, K.W. Neale, S.R. MacEwen, A. Makinde, R. Perrin, Experimental investigation of the biaxial behaviour of an aluminum sheet, International Journal of Plasticity 20 (2004) 1677-1706.

9. C.C. Tasan, J.P.M. Hoefnagels, G. Quaak, M.G.D. Geers, In-Plane Biaxial Loading of Sheet Metal until Fracture, Proceedings of the XIth International Congress and Exposition, June 2-5, (2008) Orlando, Florida USA.

10. N. Souto, A. Andrade-Campos, S. Thuillier, A numerical methodology to design heterogeneous mechanical tests, International Journal of Mechanical Sciences, http://dx.doi.org/10.1016/j.ijmecsci.2016.01.02.

11. I. Zidane, D. Guines, L. Leotoing, E. Ragneau, Development of an in-plane biaxial test for forming limit curve (FLC) characterization of metallic sheets, Measurement Science and Technology 21 (2010) 1-11.

12. W. Liu, D. Guines, L. Léotoing and E. Ragneau, Identification of sheet metal hardening for large strains with an in-plane biaxial tensile test and a dedicated cross specimen, International Journal of Mechanical Sciences 101-102, (2015) 387-398.

13. V. Grolleau, G. Gary, D. Mohr, Biaxial testing of sheet materials at high strain rates using viscoelastic bars, Experimental Mechanics, 48 (2008) 293-306.

14. M. Ramezani, Z. Ripin, Combined experimental and numerical analysis of bulge test at high strain rates using split Hopkinson pressure bar apparatus, Journal of Materials Processing Technology, 210 (2010)1061-1069.

15. A. Shimamoto, T. Shimomura, J. Nam, The development of servo dynamic biaxial loading device, Key Engineering Materials, 243-244 (2003) 99-104. 